\title{
The Dynamic Analysis of Crankshaft System of Engine
}

\author{
Jinhe Lv ${ }^{1, a}$, Yaxu Chu ${ }^{2, b^{*}}$ and Xiangwen Dang ${ }^{3, c}$ \\ ${ }^{1}$ College of Automobile\&civil Engineering of Beihua University \\ ${ }^{2}$ The Office of Academic Affairs of Beihua University \\ ${ }^{3}$ College of Automobile\&civil Engineering of Beihua University \\ alvjinhe_1987@163.com, bcyx_1964@sina.com, '844760720@qq.com \\ * The Corresponding Author
}

Keywords: Crankshaft; Piston; Main journal; Flexible support; Dynamic characteristics

\begin{abstract}
Crank and rod mechanism is the key component of the engine, and its stress variety and load distribution have an important effect on the reliability of the engine. The kinetic and kinematic responses of the crank link mechanism are studied by the coupling analysis of multi-body dynamics and static mechanics, to provide a theoretical basis for design and analysis. Research dynamic response of crankshaft system on the foundation of changing piston and crankshaft as Flesxible body. Analyse dynamic stress regulation of main journal on the basis of flexible and stress response of liquid dynamic pressure bearing all the time. Studies have shown that the pressure of the piston from the top to the piston skirt gradually reduced, the piston pin hole pressure. When the piston of a cylinder produces the impact force, the stress of the crank arm on both sides of the crankshaft increases instantaneously. The bearing oil film pressure is proportional to the change of the journal stress.
\end{abstract}

\section{Introduction}

With the development and progress of science and technology,the direction of engine toward the high-speed, high-powered, lightweight.Crankshaft is the key component of the engine,the safety and reliability and service of the engine was impacted by the quality of the crankshaft ${ }^{[1]-[3]}$. Rigid body and rigid - flexible coupling multibody dynamics analysis to crankshaft assembly has practical significance for the development of the crank assembly.It also provides a theoretical basis for new product design and development. ${ }^{[4]-[6]}$

\section{Dynamics Analysis of Crank Mechanism}

Gas Forces. Gas forces of the piston Pg corresponds to the piston, the gas pressure difference between the sides and the top surface of the piston volume product, namely.

$$
p_{\mathrm{g}}=\frac{\pi D^{4}}{4}\left(p_{1}-p_{2}\right)
$$

The reciprocating inertia force of crank:

$$
P_{j}=-m_{j} a=-m_{j} R \omega^{2}(\cos \alpha+\lambda \cos 2 \alpha)
$$

Various rotational inertia force of crank $\operatorname{Pr}$ :

$$
P_{r}=-m_{r} R \omega^{2}
$$

Decomposed into two forces: the force $\mathrm{K}$ and the axis of the piston rod is pressed against the cylinder wall lateral component, so $\mathrm{K}$ is: 


$$
K=P_{\text {合 }} \frac{1}{\cos \beta}=\frac{P_{\text {合 }}}{\sqrt{1-\lambda^{2} \sin ^{2} \alpha}}
$$

\section{Establish Three-Dimensional Solid Model of Crankshaft System}

By the size of the crank assembly of the various components, accurate rendering three-dimensional solid model of crankshaft assembly, the entire crankshaft assembly including a crankshaft, flywheel, connecting rod, piston, cylinder, main bearings and other components ${ }^{[7]-[10]}$. In the CATIA software, by fitting the relationship between the various components, the establishment of three-dimensional model of the crankshaft assembly, as shown in Fig. 1

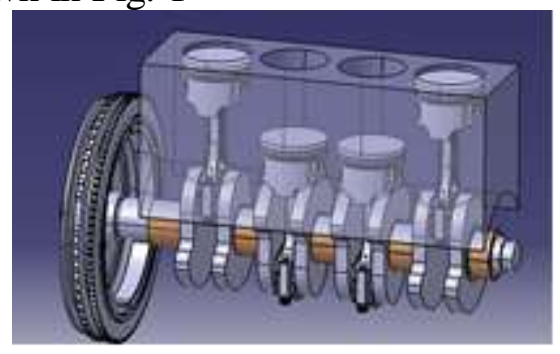

Figure 1. The crankshaft assembly three-dimensional entity model

\section{Rigid Body Model Analysis of Crankshaft Assembly}

Gas Forces. RecurDyn with most major CAD software has a seamless interface, three-dimensional solid model can be imported via an interface into RecurDyn software, rigid model for importing RecurDyn crankshaft assembly shown in Fig. 2

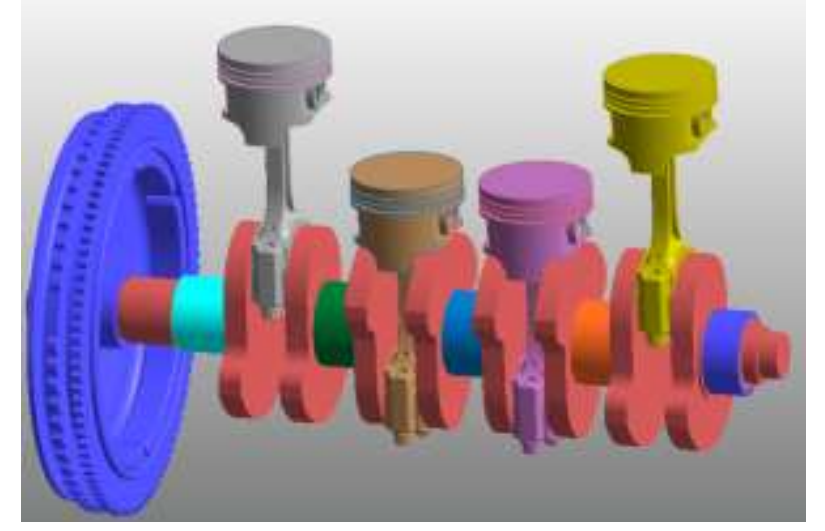

Figure 2. The coupled model crankshaft assembly

Applied Load and The Establishment of Binding. In the simulation analysis, the paper will RecurDyn mixed gas deflagration load is applied at the top of the piston, in the form of distribution of the applied force. Use Akima spline curve fitting method to create a spline interpolation function by AKISPL simulated combustion gas pressure. Shown for the gas mixture combustion pressure load spectrum data shown in Fig. 3 


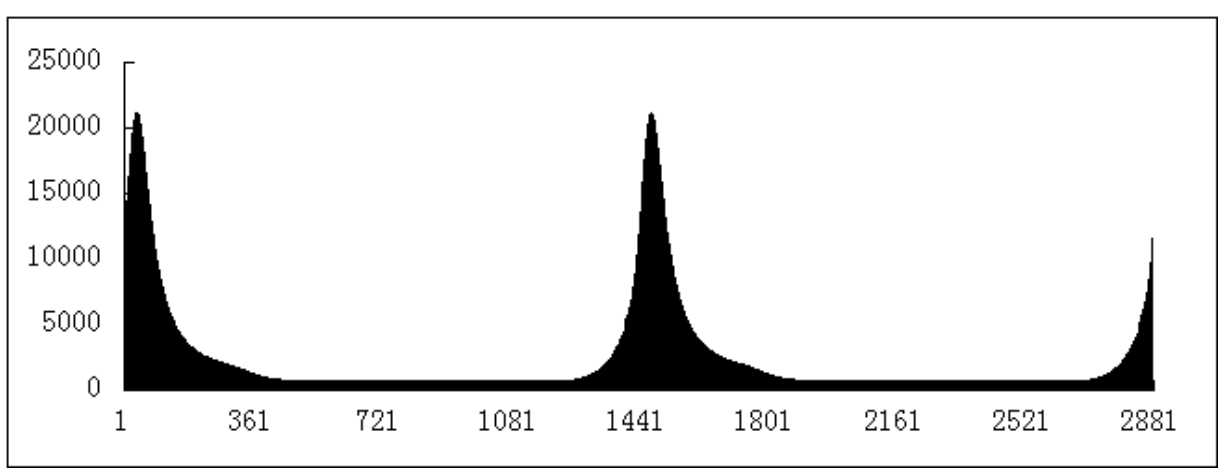

Figure 3. The mixture pressure load spectrum

Simulation Analysis. In the crankshaft assembly, the piston reciprocating motion along the cylinder wall, the piston 4 along the cylinder wall motion displacement map, the simulation results taken from a crankshaft assembly work for the study period. As can be seen from the figure, each piston reciprocates both laws.

Piston under pressure generated by gas deflagration and reciprocates along the cylinder, with the pressure changes, also changes the acceleration of the piston, the crank assembly shown in Fig. 5 during movement of the piston in a motion cycle 1,4 and acceleration curve of the piston 2, 3 can be seen from the figure, the acceleration changes periodically, with the increasing gas deflagration pressure, acceleration of the piston is also increasing.

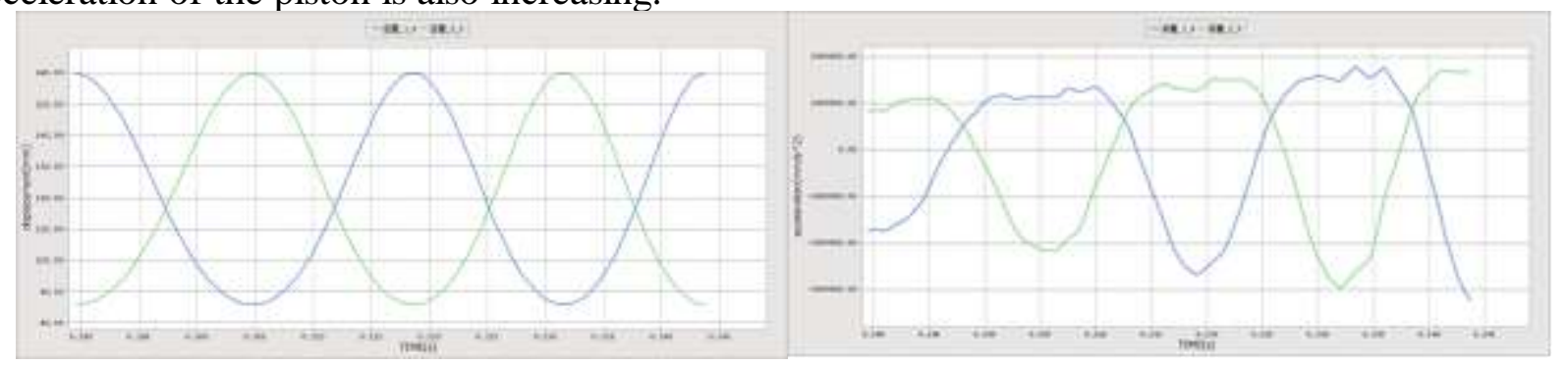

Figure 4. The piston displacement diagram

Figure 5. The piston acceleration curve

Crankshaft movement, through the spindle bearing contact with the neck, as shown in Fig. 6, the spindle neck peak loads in the mixed gas deflagration time, when a gas cylinder exploding, corresponding to the connecting rod journal on both sides of the spindle neck loads main journals load than other large load indicating rod journal is adjacent to the spindle neck respectively. As can be seen from the figure, consistent with each crankshaft main journals load trends, indicating that rigid crankshaft by a rigid support, the size of each of the main load bearing suffered less, change of load is the same. When a cylinders are firing, the spindle neck spindle neck suffered load of $13858 \mathrm{~N}, 2$ spindle neck suffered load of $4329 \mathrm{~N}$, when the three-cylinder combustion, the main journal 3 spindle neck suffered load of $5744 \mathrm{~N}$, the main journal suffered a load of $45745 \mathrm{~N}$, when the four-cylinder combustion, the main journal 4 spindle neck suffered load of $4486 \mathrm{~N}$, the main journal 5 suffered load of $4315 \mathrm{~N}$, when the two cylinders are firing, the spindle neck spindle neck suffered load of $23959 \mathrm{~N}$, suffered the main journal 3 load of 5103N.

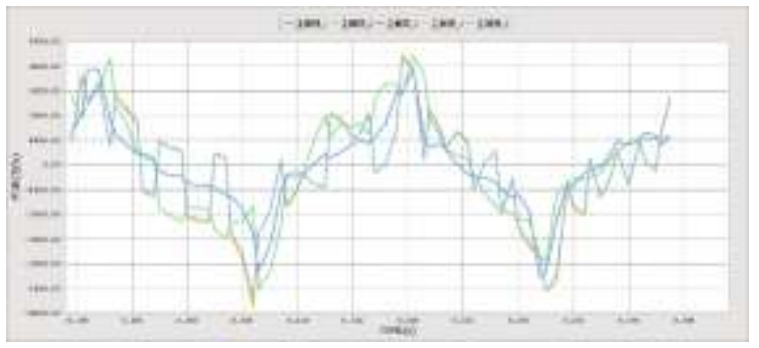

Figure 6. The piston acceleration curve 


\section{Rigid Coupling Model of Crankshaft}

Crankshaft Assembly Rigid - flexible Coupling Model. This article crankshaft and pistons arranged flexible body, other parts arranged a rigid body, so hypermesh software only for the crankshaft and pistons mesh. Then build recurdyn rigid coupling software crankshaft assembly, as shown in Fig. 7, from left to right piston 1-4

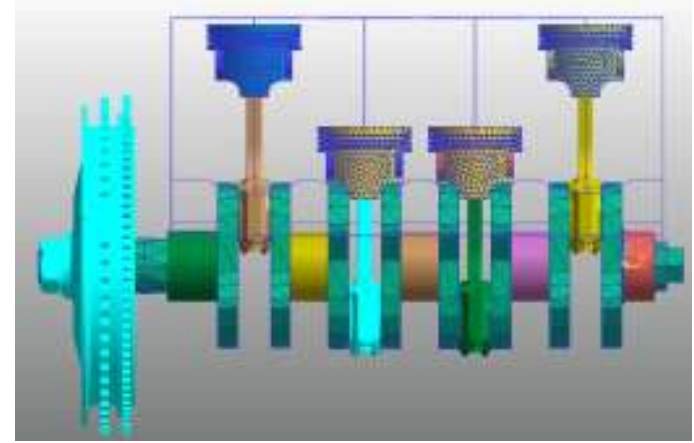

Figure 7. The coupled model crankshaft assembly

Finally, applying flexible support, namely hydrodynamic bearings, hydrodynamic bearings in which the parameters are shown in Table 1, from left to right main bearings 1-5.

Table 1 The bearing of fluid dynamic pressure parameters

\begin{tabular}{|c|c|c|c|c|}
\hline $\begin{array}{c}\text { Journal } \\
\text { diameter }(\mathrm{mm})\end{array}$ & $\begin{array}{c}\text { Bearing width } \\
(\mathrm{mm})\end{array}$ & $\begin{array}{c}\text { dynamic viscosity } \\
(\text { Pa.s) }\end{array}$ & Roughness (um) & $\begin{array}{c}\text { Oil pressure } \\
(\mathrm{N} / \mathrm{mm} 2)\end{array}$ \\
\hline 45 & 28 & 0.009 & 3 & 6 \\
\hline
\end{tabular}

Simulation Analysis. As can be seen from the figure, when a combustion cylinder, crankshaft connecting rod journal suffered load is assigned to each spindle neck, but the spindle and the spindle neck neck 12 suffered a larger load, indicating that the first link shaft most suffered neck load distribution to adjacent sides of the spindle neck, which suffered a load of spindle neck $1688 \mathrm{~N}, 2$ spindle neck suffered load of $1557 \mathrm{~N}$. When the three-cylinder combustion, the main journal 3 spindle neck suffered load of $1883 \mathrm{~N}$, the main journal 4 suffered a load of $1710 \mathrm{~N}$, when the four-cylinder combustion, the main journal 4 spindle neck suffered load of $1866 \mathrm{~N}$, the main journal suffered load of $51825 \mathrm{~N}$, when the two cylinders are firing, the spindle neck spindle neck suffered load of $22113 \mathrm{~N}$, the main journal 3 suffered load of 1663N. Compare rigid support spindle neck suffered load can be seen by hydrodynamic bearings effectively reduce the load of the spindle neck suffered.

As can be seen from Fig. 9, when the larger main journal pressure, the main bearing oil film thickness is small, and the main bearing minimum film thickness as low as 4 to $0.0082 \mathrm{~mm}$, indicating that the main journal 4 suffered the biggest load, so the spindle 4 and neck main bearing pressure between 4 large, the smallest gap. Although the main bearing minimum film thickness of only $40.002 \mathrm{~mm}$, but the spindle 2 and the main bearing neck 2 does not have a direct direct contact with dry contact or mixture shall occur. Other than the main bearing thick minimum thickness of the main bearing 4 little difference as $0.009 \mathrm{~mm}$. 5 main bearing oil film thickness changed little, indicating that the pressure on the main bearing 5 small and relatively uniform. 


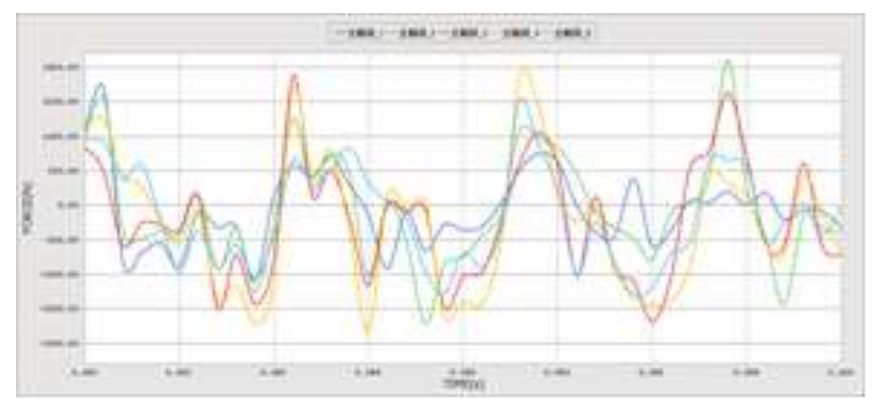

Figure 8. The crankshaft connecting rod journal load

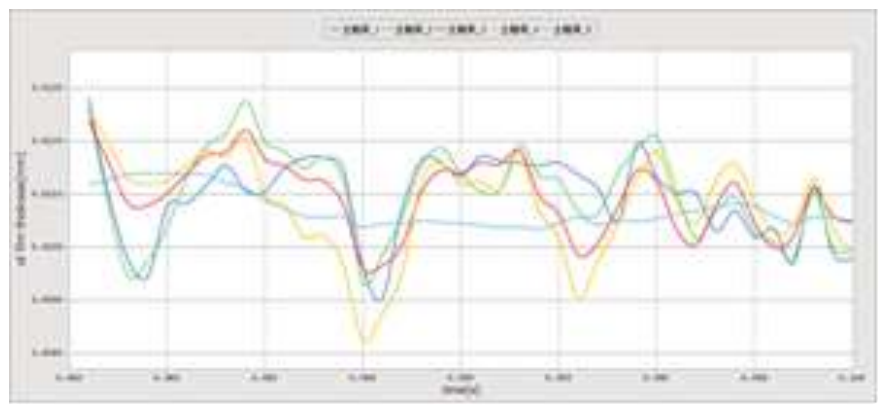

Figure 9. The main bearing oil film thickness changes

\section{Conclusion}

This paper crankshaft assembly for multi-body dynamics calculation, crankshaft assembly rigid and rigid-flexible coupling model analysis the following conclusions: under the action of the crank assembly mixed gas deflagration pressure pistons reciprocating do regularly movement. With the increase of the gas mixture deflagration pressure, movement of the piston acceleration becomes large. Compared with the rigid support, flexible support effectively reduce the load suffered crankshaft main bearings and main bearings 4 suffered maximum load, the minimum film thickness.

\section{Acknowledgements}

The 13th Five-year Science and technology project of Education Department of Jilin Province(JJKH20170030KJ)

\section{References}

[1] Liu Hai-yang,Tan Wen-jie,Li Xin.Multi-axial high cycle fatigue life estimation for diesel crankshaft[J].Journal of mechnical strength,2013,(06):844-849.

[2] Wang Feng,Chen Zheng,Li Hua.Optimization for compressor crankshaft by muti-body dynamics analysis method[J].journal of xi an jiaotong university,2017,(03):7-13.

[3] Sun Nan-nan.Research on multiaxial fatigue life criterion and the application in the crankshaft[D].Shandong university.2015:68-83.

[4] Shan Yang-zhi-shuStudy on the kinetic characteristics of engine crankshft system.Shenyang Ligong University.2015:35-70.

[5] Sun Nan-nan, Li Guo-xiang,Bai Shu-zhan.Analysi of crankshaft fatigue based on stain-life theory.Chinese internal combustion engine engineering.2014,(06):60-64+83.

[6] Cui Guang-jun.Research on co-simulation of finite element method and the multi body dynamics of the crankshaft fatigue life.Journal of mechnical strength.2016,38(2):394-398. 
[7] Xu Jian-min,Zhao Jun, Yang Huan-ying. The dynamic analysis of the internal combustion engine crankshaft and structure improvements. Manufacturing automation.2013,(17):37-39+61.

[8] Wang Fan, Yan Shi-chun,Sun Dong-yuan.Failure analysis of engine crankshaft.Heat Treatment of metals.2015,(12):194-197.

[9] Yu Qiu-hua,Liu Shu-mei,Liu Ya-hui.Design and analysis of crankshaft based on UG and ANSYS.Journal of shanghai university of engineering science.20131(04):302-305.

[10] Bao Jun,Zhang Cheng-Yan,Jiang Hui-jun.The dynamic characteristic analysis of the reciprocating compressor`s cranshaft.Machinery design\&manufacture.2015,(03):233-236. 